\title{
Uma Abordagem Interdisciplinar para o Pensamento Computacional no Ensino Fundamental
}

\author{
Crediné Silva de Menezes \\ Universidade Federal do Rio Grande do Sul (UFRGS) - PPGIE - Porto Alegre - RS \\ credine@gmail.com \\ https://orcid.org/0000-0002-2709-7135
}

\author{
Alberto Nogueira de Castro Júnior \\ Universidade Federal do Amazonas (UFAM) - PPGI - Manaus - AM \\ alberto@ufam.edu.br \\ https://orcid.org/0000-0002-1752-8667
}

\section{Resumo}

A introdução do Pensamento Computacional como uma ferramenta de apoio ao desenvolvimento da arte de resolver problemas, tem despertado o interesse de professores e pesquisadores em escala mundial. Neste artigo apresentamos uma proposta para a introdução desta temática no contexto do ensino fundamental a partir de uma abordagem interdisciplinar. Além de discutirmos os elementos embasadores da abordagem, apresentamos um exemplo para ilustrar o conceito de micromundos e uma breve discussão sobre como organizá-los.

Palavras-chave: Pensamento Computacional, Ensino Fundamental, interdiscipinaridade

\section{An Interdisciplinary Approach to Computational Thinking in Elementary School}

\begin{abstract}
The introduction of Computational Thinking as a tool to support the development of the art of problem solving, has awaked the interest of teachers and researchers worldwide. In this article we present a proposal for the introduction of this theme in the context of elementary school from an interdisciplinary approach. In addition to discussing the underlying elements of this approach, we present an example to illustrate the concept of micro worlds and a brief discussion on how to organize them.
\end{abstract}

Key-words: Computational Thinking, Elementary School, Interdisciplinarity

\section{Introdução}

Vários artefatos de hoje incluem tecnologias digitais embarcadas e dispositivos conectados, apoiados por redes de sensores e por algoritmos avançados que facilitam a reconfiguração em tempo real e a produção de novas máquinas bem mais flexíveis, ampliando bastante o alcance da tecnologia, com efeitos nem sempre positivos, como por exemplo uma significativa redução na necessidade de mão de obra em diversas áreas (Lee, 2019). Essas mudanças também deram origem ao que se tem chamado de sociedade da informação e do conhecimento e fizeram que as atenções se deslocassem para o âmbito do conhecimento. Há uma tendência de redução de empregos em tarefas repetitivas e por outro lado os problemas complexos que demandam a inteligência humana para resolvê-los. Essas novas vagas requerem um novo perfil, baseado na inovação.

Hoje é o conhecimento que se constitui no grande capital das empresas e em virtude disso evidenciou-se a necessidade de reconsiderar os processos de formação, V. $19 \mathrm{~N}^{\circ} 1$, julho, 2021 
buscando criar as condições para a formação de um "novo mundo". Já não basta o conhecimento de conteúdos, pois com isso as máquinas podem nos ajudar, o que importa é de que forma combinar o conhecimento disponível para conceber novas máquinas. $\mathrm{O}$ domínio de técnicas e estratégias para resolução de problemas complexos e de grande porte, destaca-se como o bem mais valioso.

Nos últimos 50 anos de convívio com as tecnologias digitais e de um novo parque industrial fortemente associado a ela, o conjunto de estratégias e metodologias para a concepção e implementação de artefatos gerados pela Ciência da Computação deu origem a uma tomada de consciência sobre a necessidade de socializar os princípios adotados na solução de problemas surgidos nesse contexto.

Aos fundamentos desta nova cultura convencionou-se chamar "Pensamento Computacional", que se constitui em um conjunto de princípios e estratégias que podemos usar para a modelagem e implementação de uma nova classe de soluções para problemas de qualquer natureza e nível de complexidade.

Hoje há um movimento internacional em prol da inserção dos princípios do Pensamento Computacional na educação escolar a partir dos níveis iniciais da escolarização e neste sentido diversos países buscam estratégias e enfoques para esta apropriação. Nesse contexto, buscamos contribuir para ampliar a formação de recursos humanos no tema, mantendo em perspectiva as possibilidades de integração dos princípios do Pensamento Computacional a diversas práticas individuais e coletivas.

Nesse contexto, o presente artigo destaca aspectos centrais do Pensamento Computacional (PC) relacionando-os à resolução de problemas e como isso define competências cada vez mais essenciais a nossas vidas (Seção 2), em seguida ilustramos como a concepção e desenvolvimento de "micromundos" nos ajudam a explorar problemas complexos cujos processos de solução podem ser reutilizados em diferentes cenários (Seção 3). Na Seção 4, apresentamos uma discussão sobre a elaboração de propostas de micromundos. Finalmente, na Seção 5 apresentamos as considerações finais.

\section{A Resolução de Problemas e os Pilares do PC}

Embora existam na literatura várias formas de abordar o Pensamento Computacional, há alguns aspectos que são comuns a todas elas. Um desses aspectos diz respeito à importância do PC para a resolução de problemas. Shute (2017) define o Pensamento Computacional como "o fundamento conceitual necessário para resolver problemas efetivamente e eficientemente (i.e., algoritmicamente, com ou sem a assistência de computadores) com soluções que sejam reusáveis em diferentes contextos". Esse posicionamento evidencia o papel transversal do PC nas diversas áreas do conhecimento.

A aplicação prática do Pensamento Computacional pode ser observada tanto na resolução de problemas básicos do cotidiano, como no planejamento das compras de uma família, quanto na resolução de problemas mais complexos, como na concepção de um sistema escolar, na logística de uma rede de abastecimento, na elaboração de um sistema de prevenção e erradicação de epidemias ou no envio de uma nave espacial para outro planeta.

Desde a década de 1940, as preocupações com o Pensamento Computacional já estavam presente nos trabalhos de George Polya (1945), um professor de matemática que propôs um método para resolução de problemas e um conjunto de heurísticas para apoiar o resolvedor. Seu método consiste nas seguintes etapas: Compreensão do Problema, Elaboração de um Plano; Execução do Plano e Retrospecto. Para cada uma das etapas ele apresenta várias heurísticas para orientação do resolvedor. Por exemplo, na última etapa e recomenda as seguintes indagações: É possível verificar o resultado? 
É possível verificar o argumento? É possível chegar ao resultado por um caminho diferente? É possível utilizar o resultado ou o método em algum outro problema?

Mais tarde Seymour Papert (1980), contestando a abordagem instrucionista, criou uma abordagem para construção de conhecimento que denominou de Construcionismo. Sua proposta, baseada no uso de computadores, tem como fundamentação teórica a Epistemologia Genética (Piaget, 1972). Seu trabalho tem foco na resolução de problemas a partir da exploração de um ambiente computacional onde o estudante aprende a partir de sua ação construindo objetos a partir da programação de um robô para representar objetos e procedimentos de mundos que lhe são relevantes.

Em 2006, um artigo de Jeannette Wing (2006), uma renomada cientista da computação, deu origem a um movimento internacional pela inclusão nos sistemas escolares da preparação dos cidadãos para a resolução de problemas com o uso de Pensamento Computacional. Segundo a autora, o PC consiste em um conjunto de estratégias usada por cientistas da computação na resolução de complexos problemas, tendo como suporte os computadores.

Outro aspecto relevante diz respeito ao conjunto de competências relacionadas com o estudo do Pensamento Computacional. Diferentes autores organizam esse conhecimento de diferentes formas. Shute (2017) aponta uma lista de 6 conceitos centrais: Decomposição, Abstração, Algoritmos, Depuração, Iteração e Generalização.

Vicari e outros (2018), realizaram um levantamento de alcance internacional buscando identificar os diferentes caminhos e convergências no ensino de PC. O estudo teve por base uma abrangente revisão da literatura onde os autores identificaram a convergência de quatro "pilares" fundamentais para a resolução de problemas, visão que é adotada neste trabalho. São eles:

- Abstração: A atividade de abstração consiste em selecionar os aspectos relevantes para a caracterização de um determinado objeto, com respeito a um determinado objetivo, descartando os aspectos irrelevantes.

- Decomposição: A atividade de decomposição consiste em identificar, em um objeto complexo, componentes mais simples que em sua totalidade e articulações descrevem o objeto principal.

- Reconhecimento de Padrões: Trata da identificação de objetos (coisas, processos e fenômenos) com base em um elenco abstrato de características.

- Algoritmos: Um algoritmo é uma sequência finita de atividades necessárias para resolver um determinado problema ou atingir um determinado objetivo.

Aqui fazemos um pequeno destaque sobre a resolução de problemas com a utilização dos pilares do PC. Sabemos que em muitas propostas, há uma ênfase na construção de programas a serem executados por computadores, eventualmente esta abordagem pode ser considerada como uma possibilidade a ser explorada, mas fazemos a observação que a construção de algoritmos faz parte do cotidiano e que a sua elaboração é muito importante, independentemente de sua realização em computadores. Acrescentamos a isso que os demais pilares estão presentes em nossas vidas, como elementos de suporte a organização de nossos espaços e tempos e que compreendê-los e usá-los é fundamental no processo de desenvolvimento da inteligência, no sentido defendido pela epistemologia genética (Piaget, 1972).

Podemos encontrar vários problemas de nosso cotidiano, no contexto doméstico, na organização de uma cidade, no planejamento de uma horta caseira ou de uma criação de cogumelos, que podem ser resolvidos sem usar computador, mas que requerem bastante organização cuja solução muito se apoia não apenas nos algoritmos como também nos outros 3 pilares. Um exemplo interessante é descrito em (Guedj ,1999), onde 
a organização de uma biblioteca de porte médio requer a criação de abstrações pouco convencionais e a concepção de vários tipos de estratégias.

Esses pilares do PC podem ser usados em diferentes circunstâncias na resolução de problemas. Nossa abordagem considera a exploração de "micromundos" configurados de múltiplas formas, de modo a exercitar e analisar o uso dos pilares na resolução das várias instâncias de problemas.

Os pilares do PC também podem auxiliar a colaboração entre diferentes atores envolvidos em um processo bem como auxiliar a estabelecer ligações entre diferentes áreas, como discutido a seguir.

\subsection{O Pensamento Computacional e a Cooperação}

Certamente cada um de nós já tomou parte, em algum momento da vida, de uma ação ou atividade em que um objetivo comum foi estabelecido e cada membro de um grupo investiu esforço e/ou recursos diversos para sua concretização. Talvez um "mutirão" para revitalização de um prédio ou instalação de uso comum, uma ação para angariar fundos para uma causa reconhecida por seus méritos, ou a formação de um grupo para realizar trabalhos acadêmicos, na busca por compreender temas complexos, estudar para uma prova ou mesmo para se preparar para um concurso. Defendemos que o uso dos pilares computacionais pode auxiliar a entendermos e praticarmos ações dessa natureza.

A Decomposição de um problema em partes mais elementares possibilita tornar explícitas as tarefas requeridas para a solução de um problema, além de facilitar a comunicação entre os atores envolvidos e a percepção do progresso individual e total. Um aspecto decisivo nas ações cooperativas é a distribuição das tarefas a membros do grupo, que deve ser resultado do casamento entre cada tarefa a aspectos característicos ou desejáveis do agente humano responsável pela sua realização.

Embora possa à primeira vista parecer simples, isso envolve a identificação dos requisitos da tarefa e das características (habilidades, competências, potencialidades, preferências etc.) do agente humano envolvido. Essa necessidade de representar os elementos da realidade considerada com foco na realização da tarefa por um agente humano, é um exemplo da importância do pilar Abstração no planejamento de atividades cooperativas.

Ações cooperativas necessariamente envolvem a interação entre os membros do grupo e a realização de atividades coordenadas que são resultado dessas interações. Há, entretanto, contextos de interação que não contribuem ou prejudicam o trabalho, tornando-se por isso indesejáveis, como a conversa cíclica (sem avanços), o debate estagnado (impasse), a discussão desordenada, dentre vários outros. Identificar tais situações através dos recursos discutidos no pilar Reconhecimento de Padrões também é determinante para a cooperação.

Ainda considerando a dinâmica interacionista mencionada no último parágrafo, podemos pensar em como organizá-la segundo um conjunto de instruções precisas de passos a serem seguidos, um Algoritmo (ou script) que facilite e caracterize a ação cooperativa sendo realizada, algumas vezes constituindo-se em elemento central de um "método" cooperativo.

\subsection{O Pensamento computacional e a Interdisciplinaridade}

Os pilares do pensamento computacional podem ser aplicados na resolução de problemas em um número variado de contextos, o que pode contribuir para a realização de estudos interdisciplinares.

O Pilar Abstração contribui para que, ao modelamos um objeto de estudo de várias disciplinas, sejam consideradas as diferentes formas de percebê-lo, identificando 
inclusive os aspectos que interessam a mais de uma área, evitando assim o tratamento isolado de um mesmo objeto. Esse Pilar apoia ainda a identificação de abstrações de dados que podem ser usadas para modelar objetos de diferentes disciplinas, como um grafo, que pode ser usado para modelar uma rede de vias de ligação entre diferentes pontos de uma cidade, uma rede de interações entre os participantes de um grupo social e até uma rede de dependências entre diferentes etapas de um cronograma.

O Pilar Decomposição auxilia na identificação de diferentes subconjuntos de funcionalidades de um objeto, permitindo a exploração enquanto um objeto independente, ao mesmo tempo que considera as suas interfaces.

O Pilar Reconhecimento de Padrões apoia a modelagem de objetos decompostos na busca pela identificação de estruturas conhecidas, em diferentes áreas do conhecimento que possam facilitar a exploração dos elementos resultantes da decomposição. Além disso, padrões e consequentemente, seus reconhecimentos, ocorrem nos mais diversos domínios do conhecimento, o que possibilita um intercâmbio entre diferentes campos de aplicação.

O Pilar Algoritmos pode facilitar o intercâmbio entre saberes, ao usar uma linguagem padronizada para falar sobre processos. Além disso, um mesmo algoritmo pode ser transposto para diferentes domínios do conhecimento.

Na próxima seção discutimos como a exploração de micromundos e dos vários problemas definidos a partir deles pode fundamentar o desenvolvimento de competências baseado no uso dos pilares do PC, analisando essas questões no cenário de formação de professores atuando no Ensino Fundamental.

\section{A inserção do Pensamento Computacional no Ensino Fundamental}

Papert (1980) ao falar sobre pensamento computacional, não buscava a criação de uma nova disciplina para ser inserida nos currículos do ensino fundamental. Ele estava envolvido com a elaboração de uma abordagem conceitual que oferecesse às crianças e adolescentes apoio à resolução de problemas interdisciplinares, ou seja, problemas que requerem o conhecimento de diferentes áreas do saber. Os trabalhos de Papert com as crianças foi focado na organização do conhecimento usando uma ferramenta lógica para expressar essa organização. O interesse não era representar o conhecimento de diferentes saberes através de programas de computador e sim, usar ferramentas conceituais do contexto da ciência da computação para apoiar a compreensão do mundo a partir de sua exploração.

Entendemos que a resolução de problemas do mundo real requer o estudo de diferentes áreas do saber, a compreensão seus objetos, processos e fenômenos e que todos esses estudos podem ser realizados com o apoio de ferramentas conceituais como por exemplo os Pilares do Pensamento Computacional.

\subsection{Explorando o cotidiano a partir de recortes}

$\mathrm{O}$ estudo do Pensamento Computacional por crianças e adolescentes pode ser explorado com maior eficácia se não repetirmos a tradicional organização curricular em conteúdos, ou seja, estudar os temas separadamente e com isso apresentar os problemas isoladamente. Nesse sentido, emprestamos um termo usado por Papert (1980) em seu seminal livro, onde ele sugere que as crianças construam conhecimento a partir da exploração de um "micromundo", que no caso de Papert, tratava-se de um espaço habitado por um robô de superfície, para explorar a construção de conhecimento através da cognição situada, em uma abordagem pedagógica denominada por ele de "construcionismo". Em suas palavras:

The Turtle World was a microworld, a "place", a "province of Mathland", where certain kinds of mathematical thinking could hatch and grow with particular ease. The microworld was an 
incubator... The design of the microworld makes it a "growing place" for a specific species of powerful ideas or intellectual structures. (Papert, 1980, p. 125)

Em nosso caso, escolhemos um outro caminho e usamos o mesmo termo para falar de recortes do mundo real onde os estudantes, com o apoio dos professores, descobrem e exploram o mundo à sua volta, através de recortes que denominamos de micromundos. Assim, em nossa proposta a ideia é descrever contextos conhecidos, para que observando o que está descrito possamos pensar com mais clareza. Esses micromundos podem ser descritos de forma cooperativa, usando ferramentas da web, formando comunidades de professores e estudantes que podem criar, recriar e compartilhar centenas de micromundos para apoiar o trabalho escolar.

Nesse sentido outros autores (Flor e Pinheiro, 2020; Jenkins, 2012) já buscam a transposição da ideia de Seymour Papert levando a concepção de micromundos para além do mundo do robô tartaruga da linguagem LOGO, mantendo, entretanto, a conexão com a proposta da abordagem construcionista. É neste sentido que se situam as seguintes afirmações:

Instructionism is the theory that says, "To get better education, we must improve instruction. And if we're going to use computers, we'll make the computers do the instruction." And that leads into the whole idea of computer-aided instruction. (Papert, 1980b apud Jenkins, 2012)

[...] um outro nível de construção do conhecimento: a construção do conhecimento que acontece quando o aluno elabora um objeto de seu interesse, como uma obra de arte, um relato de experiência ou um programa de computador (Valente, 1993, p. 40).

\subsection{Explorando Micromundos}

Uma abordagem possível para o desenvolvimento de competências é a utilização de "situações" com as quais um interessado ("aprendente") poderia estabelecer conexões com sua realidade específica. Tais situações seriam recortes do mundo real, denominados de "micromundos" e envolveriam atores, objetos, relações e eventos diversos, selecionados de modo a explorarmos os diversos tipos e níveis de complexidade envolvidos bem como as possibilidades de solução possíveis.

Para nós, um micromundo é um contexto complexo, onde é possível explorar situações que envolvam conhecimentos de diferentes áreas do saber, favorecendo assim a vivência com o conceito de Interdisciplinaridade.

A intenção não é oferecer modelos para que o professor os aplique a seus alunos de forma descontextualizada, mas trazer ideias de como se pode explorar um determinado recorte do mundo.

Um micromundo deve explorado destacando eventos relevantes, ou seja, acontecimentos sociais, onde os personagens devem realizar atividades significativas, individualmente ou em cooperação.

Para cada micromundo selecionado é recomendado a elaboração de um cenário bem amplo, buscando com isso oferecer aos estudantes a possibilidade de explorar os micromundos a partir de suas diferentes expectativas.

Quando possível, devemos ir além das descrições narrativas e construir micromundos com maquetes físicas ou digitais, apresentar vídeos e outras mídias que apoiem a percepção dos alunos e acentuem seus interesses. Para tanto, a participação dos alunos de uma determinada turma é fundamental e, quando possível, deve contar com a colaboração de alunos de turmas mais avançadas. Visitas de campo e/ou realização de eventos na escola também podem ampliar significativamente os benefícios.

Devemos considerar todas essas possíveis oportunidades para explorar os conceitos de resolução de problemas, enriquecidos pelo aporte das ferramentas do Pensamento Computacional. 
Cada micromundo serve como base para a caracterização de eventos e a cada evento pode ser associado uma ou mais situações-problema que por sua vez são instanciadas em diversos problemas cuja resolução é desenvolvida utilizando-se os pilares do Pensamento Computacional. Usar esses micromundos para exemplificar como os pilares podem apoiar o processo de resolução de problemas em contextos e níveis variados é o principal objetivo de nossa proposta. Mais adiante apresentamos o processo que utilizamos para a definição e exploração desses micromundos, a engenharia subjacente, de tal modo que um aprendente possa gerar suas próprias instâncias, conforme julgar interessante ou apropriado. Essa estrutura é mostrada na Figura 1.

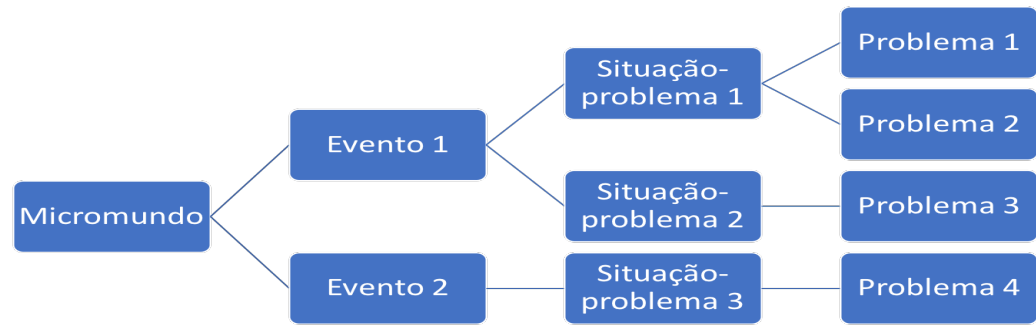

Figura 1 - Exemplo de estrutura de problemas baseada em micromundo

\subsection{Um Exemplo de Micromundo: "Feira Livre e Similares"}

A feira livre é uma modalidade de comércio que data de épocas bastante remotas. Originalmente, a feira era um dos poucos locais disponíveis para que os moradores de uma cidade ou região pudessem trocar as mercadorias produzidas em suas propriedades por outras que lhes interessavam, mas que não produziam. Ao longo da história, as feiras livres foram incorporando outros elementos, agregando motivos importantes para que as pessoas se decidam frequentá-las, como conhecer pessoas, conhecer produtos, trocar objetos manufaturados (incluindo artesanatos), saber das novidades, discutir política etc.

Apesar de hoje já existirem vários outros espaços para a realização dessas atividades, como os mercados, as mercearias e os supermercados, as feiras livres continuam a existir. Uma grande vantagem das feiras livres é que cada feirante é um comércio à parte, com características definidas por cada um proprietário. Apesar de os produtos comercializados nem sempre serem produzidos na propriedade do feirante, $o$ encanto e a praticidade das feiras continuam presentes.

Hoje, o conceito de feira passou a ser usado em diferentes situações de comércio, inclusive no mundo digital, seja para venda ou para simples apresentação de novos produtos ou para aproximar produtores e consumidores. Em muitas cidades encontramos hoje feiras beneficentes, feiras do livro, feiras para liquidação de estoque, feiras agropecuárias e até mesmo feiras de ciências.

$\mathrm{Na}$ escola, podemos elaborar diferentes eventos e situações-problema para apoiar o desenvolvimento dos estudantes nas diversas áreas de conhecimento consideradas pela legislação relacionada. Desde um simples passeio de reconhecimento, passando por uma saída para compras, uma visita para conversar com trabalhadores e até mesmo na concepção e organização de feiras temáticas, encontramos excelentes oportunidades de aprendizagem.

$\mathrm{Na}$ cidade do Rio de Janeiro por exemplo, existem várias feiras livres, com diferentes orientações econômicas, sociais ou culturais. Uma bem conhecida, muito rica em oportunidades de aprendizagem, do ponto de vista cultural, é a feira de São Cristóvão, que oferece aos seus visitantes a possibilidade de conhecer os produtos agrícolas e artesanais da região Nordeste. 


\subsubsection{Aplicando os Pilares}

A seguir ilustramos problemas específicos no contexto de duas situações-problema e de um evento definido como uma particularização do micromundo descrito anteriormente. A apresentação final do problema (contextualização, questões específicas etc.) depende da organização e estratégias adotadas em cada situação. Na resolução de cada problema indicado apresentamos a sugestão de pilares cujo uso pode dar boas contribuições para a solução.

\section{Evento 1: "Uma Feira Beneficente"}

Com o propósito de apoiar a consolidação de um clube de artesãos do bairro, uma escola concordou em ajudar na comercialização de produtos criados pelos artesãos ou doados pelas famílias dos estudantes. Conseguiu-se que a administração municipal fornecesse barracas e licenciamento para que os produtos fossem comercializados como uma extensão da feira livre realizada no bairro. O planejamento e realização dessa "feira beneficente" envolve um conjunto de atividades desenvolvidas por diversos voluntários da escola, dos estudantes e seus familiares e dos próprios artesãos.

\section{Situação-problema 1: "Organizando as barracas"}

A administração municipal cedeu uma certa quantidade de barracas e orientou a coordenação da feira beneficente sobre as regras envolvidas (espaçamento mínimo, pontos de energia, espaço para circulação de pedestres, acesso de veículos para carga e descarga etc).

\section{Problema 1: "Formação das equipes"}

As equipes de voluntários serão formadas de acordo com as etapas que atuarão, por exemplo: transporte (ida/volta), montagem/desmontagem, venda (organizada em turnos), contabilidade, apoio (alimentação, logística etc).

Pilar sugerido: Decomposição

\section{Problema 2: "Organização dos produtos"}

Cada barraca irá acomodar produtos com características semelhantes, definidas segundo sua natureza ou aplicação, por exemplo: alimentos, vestuário, acessórios de casa, ferramentas etc.

Pilar sugerido: Reconhecimento de Padrões

\section{Situação Problema 2: "Definindo preços"}

Os produtos que serão comercializados na feira beneficente são de várias naturezas e podem ser novos ou usados. Cada barraca deve ter sua lista de preços que orientará a negociação. Nessa tabela, a cada item deve ser associado um valor padrão e "redutores" que orientem a negociação.

\section{Problema 3: "Construindo uma tabela de preços"}

O preço de cada item a ser comercializado depende da categoria a que pertence e a aplicabilidade de "redutores". Por exemplo, a aquisição de três ou mais unidades de produtos de uma mesma categoria dá direito a uma redução de $20 \%$ no valor pago. Produtos artesanais têm um valor padrão (definido previamente utilizando o menor valor de mercado em produto similar como máximo) e um valor mínimo, que pode atingir até $30 \%$ de redução dependendo da negociação.

Pilares sugeridos: Reconhecimento de Padrões e Algoritmo 


\section{Discutindo a "Engenharia" dos Micromundos}

É importante destacar que não propomos apresentar aqui um conjunto de tarefas precisamente definidas e sequenciadas cuja execução resultaria na inequívoca produção de um micromundo válido e apropriado. Tampouco apresentamos um algoritmo para a produção de micromundos, mas podemos ilustrar algumas diretrizes de ação descritas em nível geral e pouco aprofundado ("alto nível" ou "macro nível").

Sugerimos iniciar o processo de criação pela definição mais geral do "domínio" (micromundo) a ser explorado, caracterizando-o através de situações conhecidas, apoiado por uma narrativa em linguagem coloquial. A partir disso, identificamos eventos que podem inclusive ser relevantes para o contexto de uma sala de aula e, para cada evento identificamos situações-problema. Estas situações podem dar origem à especificação de vários problemas que podem ser concebidos pelos aprendentes.

\section{Discussão e Considerações Finais}

Acreditamos que a construção de competências no uso do pensamento computacional não deve se restringir ao uso de computadores, mas primariamente nos conceitos básicos sobre como organizar o pensamento para resolver problemas de todas as áreas do conhecimento considerando um elenco de estratégias.

O desenvolvimento dessas competências deve ser incentivado desde os anos iniciais da escolarização. Isto requer que professores do ensino fundamental estejam familiarizados com esta abordagem para resolver problemas, notadamente em suas áreas de conhecimento e que busquem incorporá-las em suas propostas pedagógicas.

Neste artigo apresentamos uma abordagem pedagógica para a construção de competências para resolução de problemas baseada no uso dos pilares do PC como ferramenta básica para a exploração de problemas definidos a partir de micromundos concebidos de modo a aproximá-los da realidade do aprendente.

Usando esta abordagem construímos uma proposta de cursos que tem sido oferecido em uma plataforma pública para formação de professores. Esses cursos contaram, até o momento, com a participação de mais de 15.000 professores.

\section{Referências}

Cuny, Jan, Snyder, Larry and Wing, Jeannette. Demystifying Computational Thinking for Non-Computer Scientists, work in progress, 2010.

Flor, A.F., Ribeiro, R.J. Revista Brasileira de Ensino de Ciências e Tecnologia, v. 13, n. 2, Ponta Grossa, 2020.

Jenkins, C. W. Microworlds: Building Powerful Ideas in the Secondary School, USChina Education Review, 2012.

Lee, K. Inteligência Artificial: como os robôs estão mudando o mundo, a forma como amamos, nos relacionamos, trabalhamos e vivemos. Globo Livros, Rio de Janeiro, 2019.

Papert, S. Mindstorms: Children, Computers and Powerful Ideas, Basic

Books Pubs., New York, 1980.

Piaget, J. Psicologia e Epistemologia Genética, Editora Forense, 1972.

Polya, George. How to Solve It. Princeton University Press, 1945.

Shute, V. J., Sun, C. \& Asbell-Clarke, JDemystifying computational thinking. Educational Research Review, 22(September), p. 142-158, 2017. 
VALENTE, J. A. Diferentes usos do computador na educação. Computadores e conhecimento: repensando a educação. Campinas: NIED-Unicamp, 1993.

Vicari, R.M., Moreira, A., Menezes, P.B. (2018) Pensamento Computacional - Revisão Bibliográfica, UFRGS/MEC. Disponível em

https://lume.ufrgs.br/bitstream/handle/10183/197566/001097710.pdf acessado em 31/07/2020.

Wing, Jeannette. Computational Thinking (Viewpoint). Communications of the ACM. Vol. 49, No. 3, p. 33-35, 2006.

Guedj, D. O Teorema do Papagaio: Um Thriller da História da Matemática, Cia da Letras, 1999. 